ORIGINAL ARTICLE

\title{
My sibling, my weight. How gender, sibling gender, sibling weight and sibling weight level perception influence weight perception accuracy
}

\author{
VT Christensen
}

OBJECTIVE: The objective of this study was to examine the impact of sibling weight level perception and sibling weight on the accuracy of respondent weight level perception dependent on sibling-pair gender composition.

DESIGN: A cross-sectional study based on the survey data, which include the children of a nationally representative sample of Danes. Logit regression models were used.

SUBJECTS: Two thousand nine hundred and sixty-eight respondents comprising 397 female sibling pairs, 357 male sibling pairs and 730 opposite-sex sibling pairs. The inclusion of both same-sex siblings and opposite-sex siblings is novel for studies on weight perceptions.

MEASUREMENTS: Weight underestimation and weight overestimation were calculated on the basis of difference between actual weight level and self-perceived weight level. Respondent gender, sibling gender, sibling body mass index (BMI) and the siblings' self-perceived weight level were included as the main controls.

RESULTS: Women frequently overestimate their weight level, whereas men often underestimate theirs. Women are more likely to overestimate their weight if their sister does the same but less likely if their brother overestimates his weight. Likewise, women are more likely to underestimate their weight if their sister also underestimates her weight but less likely if their brother underestimates his weight. The higher the BMI of their brother and the lower the BMI of their sister, the more likely men are to underestimate their own weight level.

CONCLUSION: Results underline the importance of social context when looking at body formation and weight perceptions. The weight and weight perceptions of siblings influence own weight perception. Gender is central to studies on weight-related issues, not only respondent gender - equally so the gender of interaction.

Nutrition \& Diabetes (2014) 4, e103; doi:10.1038/nutd.2013.44; published online 13 January 2014

Keywords: weight perception; BMl; gender; siblings; opposite-sex pairs; logit regression

\section{INTRODUCTION}

In an effort to understand the increase in overweight and obesity rates in recent decades, ${ }^{1}$ researchers have started looking at the role body image has with regard to weight management and weight levels. Body image takes on varying definitions, such as weight satisfaction, appearance satisfaction and size perception accuracy. ${ }^{2}$ Focusing on the perceptual component of body image, research has shown weight level perception to be a significant predictor of weight management behaviour. ${ }^{3}$ Individuals who perceive themselves as overweight are more likely to attempt weight $\operatorname{loss}^{4}$ than individuals perceiving themselves as normal weight. However, when investigating the accuracy of body size perception relative to actual size, research shows that a substantial proportion of adults assess their weight status incorrectly. ${ }^{5}$ With excess weight as a potential health risk factor ${ }^{6}$ and perception of excess weight being a prerequisite for making changes so as to lose weight, an accurate weight assessment is crucial. On the other hand, misperceived overweight and body dissatisfactions have potential physical and psychological consequences, as seen with, for example, anorexia. Therefore, more research on weight level perceptions and the development hereof is needed to understand the complexity of obesity and weight level developments as well as the consequences of weight perceptions and body image ideals.

Cash $^{7}$ states that socialisation is fundamental for body weight and body image developments. The social context-the social, cultural, historical and physical setting-in which the individual operates as well as interpersonal relationships contribute greatly to the socialisation of the body prescribing certain values, standards and expectations with regard to body images and bodily perceptions. ${ }^{8,9}$ According to family system theory, families live in complex systems with multiple simultaneous interactions where not only the actions and behaviours of each family member are shaped by but also shape the actions and behaviours of other family members. ${ }^{10}$ Accordingly, research suggests body image to be formed in childhood. ${ }^{2}$

There is a significant correlation in weight levels for siblings in childhood as well as adulthood.11,12 And although genetic contributions appear substantial, with studies indicating heritability estimates of $40-90 \%,{ }^{13}$ research has also shown that common environmental factors and shared parental and family domains have a significant part concerning sibling-correlated body mass index (BMI) levels and population variations in BMI levels. ${ }^{14-17}$

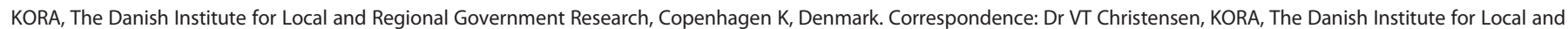
Regional Government Research, Købmagergade 22, Copenhagen K 1150, Denmark. 
Price and Swigert ${ }^{18}$ document a considerable amount of variation in body weight between siblings, even twins, and therefore stress the potential for research on factors influencing within-family differences in weight and obesity. As such, both genetic and social factors have a part concerning family weight similarities, but the significance of the behavioural, cultural, environmental and social conditions must not be overlooked or underestimated. ${ }^{19}$ Furthermore, siblings are shown to provide significant social comparison standards for individual weight, ${ }^{20}$ body image developments ${ }^{21}$ and bodily satisfactions $\mathrm{s}^{22}$ in adulthood.

Viewing body image as a social construct, gender becomes a fundamental parameter with clear gender-differentiated norms with regard to femininity and masculinity and thereto connected weight levels. ${ }^{2}$ Significant gender differences in weight level perceptions have been established in previous literature. Empirical research shows that women are less frequently overweight, ${ }^{23}$ but more often perceive themselves as overweight. ${ }^{24,25}$ Connecting research on gender and sibling weight levels, Price and Swigert ${ }^{18}$ show that siblings of the same gender tend to be more similar to each other in BMI than opposite-gender sibling pairs, irrespective of status as twins or non-twins. Likewise, Jacobson and Rowe ${ }^{26}$ find that weight correlations for same-sex siblings are higher than those for opposite-sex siblings. Moreover, Dubois et al. ${ }^{13}$ find sex differences in the heritability of body weight, with common environmental factors having a more important role for girls than boys in explaining the variability in BMI. According to Jacobson and Rowe, ${ }^{26}$ one explanation for this result could be the greater likelihood of engaging in weight control strategies for women, and thus sisters will exert a greater mutual influence on each other with regard to body image as well as weight and exercise behaviours compared with brothers with less interest in weight control strategies.

Drawing on these findings with regard to sibling influences on weight as well as gender-differentiated weight level perceptions and body images, this paper extends on previous research by examining the impact of sibling gender composition, sibling weight and sibling weight level perception on accuracy in adult weight level perceptions. The supposition is that siblings influence each other in childhood as well as adulthood with significant impact on adult weight levels and perceptions.

The study has a quantitative approach using logit regression models and is based on Danish survey data, which include the children of a nationally representative sample of respondents. Having data on sibling pairs that include same- and opposite-sex siblings, I wish to study whether growing up with a sibling of the same gender impacts on weight level perceptions in adulthood differently from individuals who grow up with a sibling of a different gender-and whether there is a difference between men and women. I will, furthermore, study how the weight level and weight level perception of one's sibling impact on own weight level perception in the interaction with sibling gender and own gender. On the basis of previous findings and theory, it could be expected that siblings of the same gender exert a greater impact on weight level perceptions than siblings of a different gender, with women especially being aware of weight levels and weight expectations. To my knowledge, no previous studies have taken this approach to weight level perceptions including both sameand opposite-sex sibling pairs and looking at within- and acrosssex effects. With the inclusion of sibling gender composition in an analysis of accuracy in weight level perceptions, I hope to develop understanding about how bodies and body formation are affected by social processes, and gender interactions gaining important knowledge for understanding weight developments.

\section{MATERIALS AND METHODS}

The study was based on data from the Danish Longitudinal Survey of Youth-Children (DLSY-C). The data were collected in 2010. The DLSY-C includes children of participants in a long-running cohort study, the Danish Longitudinal Survey of Youth (DLSY). The DLSY includes about 3100 participants all born in or around 1954. The DLSY-C samples all children born to DLSY respondents and had a response rate of $81 \%$. The DLSY-C includes 3519 respondents. ${ }^{27}$

In the analyses, I included all sibling pairs irrespective of the number of siblings in the family. I looked at each sibling pair separately. There are 1838 sibling pairs in the data set. I excluded 307 sibling pairs with a minimum of one of the siblings being under the age of 18 years because the weight level of children and adolescents is calculated differently from that of adults. In addition, I excluded 47 sibling pairs with missing values on weight, height or self-perceived weight level for a minimum of one of the siblings. As a consequence, the final analysis sample included 2200 unique respondents. However, with some respondents having more than one sibling, there were 2968 respondents and 1484 sibling pairs in the data. One thousand five hundred and sixty-two respondents had one sibling, 540 respondents had two siblings, 72 respondents had three siblings, 20 respondents had four siblings and 6 respondents had five siblings. Three hundred and ninety-seven sibling pairs were female, 357 sibling pairs were male and 730 sibling pairs were mixed.

\section{Dependent variables}

I used two dependent variables in the analyses. The first dependent variable, weight underestimation, was defined as the degree of difference between actual weight level and self-perceived weight level, with the value of 1 if the respondents underestimated their weight and 0 if they did not The actual weight level was determined by the BMI. The BMI is calculated by dividing weight in kilogrammes by height in metres squared. According to international standardisations, a BMI below $18.5 \mathrm{~kg} \mathrm{~m}^{-2}$ is considered underweight, a BMI between 18.5 and $24.9 \mathrm{~kg} \mathrm{~m}^{-2}$ is normal weight, a BMI between 25 and $29.9 \mathrm{~kg} \mathrm{~m}^{-2}$ is overweight, a BMI between 30 and $34.9 \mathrm{~kg} \mathrm{~m}^{-2}$ is obese and a BMI of $35 \mathrm{~kg} \mathrm{~m}^{-2}$ and above is morbidly obese. $^{1}$ Weight and height of the respondent were self-reported. Selfreported weight and height are subject to measurement error, with a tendency for people to under-report their weight or overestimate their height. $^{28,29}$ I used corrected measures of BMI to improve accuracy of the variable. Several researchers have developed corrections for self-reported height and weight. ${ }^{30,31}$ I used algorithms developed by Nyholm et al. ${ }^{32}$ based on Swedish data as previous studies have shown self-rated measures to be analogue in the Scandinavian countries. ${ }^{33}$ The selfperceived weight level was based on answers to the question: 'How do you assess your own weight?', with choices of the answer being underweight, normal weight, somewhat overweight, overweight and very overweight.

The second dependent variable, weight overestimation, was also defined as the degree of difference between actual weight level and self-perceived weight level, with the value of 1 if the respondents overestimated their weight and the value of 0 if they did not. Value assignments for respondent weight underestimation and overestimation based on actual weight level and self-perceived weight level can be seen in Table 1.

Table 2 shows weight level distributions, self-perceived weight levels and the degree of weight underestimation and weight overestimation for all respondents and separately for women and men.

Men have a somewhat higher BMI average (mean $=25.0$, s.d. $=4.4$ ) than women (mean $=24.1$, s.d. =5.1). More women than men belong to the underweight and normal weight categories, whereas more men than women are overweight or obese. However, in the category morbidly obese, the percentage is somewhat higher for women than for men. Compared with women, men have a greater tendency to underestimate their weight level, whereas women more often than men overestimate their weight level. There is a significant correlation in sibling BMI ( $r=0.369$, $P=0.000)$.

\section{Independent variables}

The main independent variables were sibling gender (a binary dummy variable for brother), sibling BMI, sibling weight underestimation and sibling weight overestimation. Sibling BMI was mean centred for the analyses. In addition to the main independent variables, I also included a range of control variables for the respondent. I included control variables measuring respondent $\mathrm{BMI}$, age in years, educational attainment (binary dummy variables for six educational levels) and marital status (a binary dummy variable for being married or cohabitating). I, furthermore, included a binary control variable for a sibling age gap of 5 years or less compared with more than 5 years, a control variable for whether or not the 
siblings both lived with their biological parents during their childhood and hence grew up together, and a control for the number of siblings in the family. There are no significant differences in mean BMI $(P=0.264)$, mean underestimation $(P=0.862)$ and mean overestimation $(P=0.559)$ for the number of siblings. Table 3 provides summary statistics.

\section{Statistical analysis}

I estimated three regression models for both dependent variables using logit regression models as both my dependent variables were binary. In the first model (Model I), I regressed the dependent variable on sibling gender, sibling BMI and the control variables. In the second model (Model II), I included sibling weight underestimation and sibling weight overestimation. In the third model (Model III), I, furthermore, included an

Table 1. Values for weight underestimation and overestimation based on actual weight level and self-perceived weight level

\begin{tabular}{|c|c|c|c|c|c|}
\hline & \multicolumn{5}{|c|}{ Self-perceived weight level } \\
\hline & $\begin{array}{l}\text { Under- } \\
\text { weight }\end{array}$ & $\begin{array}{c}\text { Normal } \\
\text { weight }\end{array}$ & $\begin{array}{l}\text { Somewhat } \\
\text { overweight }\end{array}$ & $\begin{array}{c}\text { Over- } \\
\text { weight }\end{array}$ & $\begin{array}{l}\text { Very over- } \\
\text { weight }\end{array}$ \\
\hline \multicolumn{6}{|l|}{ Underestimation } \\
\hline \multicolumn{6}{|l|}{ Weight level } \\
\hline Underweight & 0 & 0 & 0 & 0 & 0 \\
\hline Normal weight & 1 & 0 & 0 & 0 & 0 \\
\hline Overweight & 1 & 1 & 0 & 0 & 0 \\
\hline Obese & 1 & 1 & 1 & 1 & 0 \\
\hline Morbidly obese & 1 & 1 & 1 & 1 & 0 \\
\hline \multicolumn{6}{|l|}{ Overestimation } \\
\hline \multicolumn{6}{|l|}{ Weight level } \\
\hline Underweight & 0 & 1 & 1 & 1 & 1 \\
\hline Normal weight & 0 & 0 & 1 & 1 & 1 \\
\hline Overweight & 0 & 0 & 0 & 0 & 1 \\
\hline Obese & 0 & 0 & 0 & 0 & 0 \\
\hline Morbidly obese & 0 & 0 & 0 & 0 & 0 \\
\hline
\end{tabular}

interaction effect between sibling gender and sibling BMI, an interaction effect between sibling weight underestimation and sibling gender and an interaction effect between sibling weight overestimation and sibling gender to test whether the effects of sibling BMI and sibling weight estimations vary according to sibling gender. All analyses were performed separately for women and men. I included the different interaction effects to fully understand the manner in which respondent characteristics and sibling characteristics with regard to gender, weight and weight level perceptions interact and intertwine. I used STATA's logit command for the regression models, and report log odds and robust standard errors. I adjusted standard errors to account for design effects of clustering between siblings. Significance at the $10 \%$ level is also reported in the next section.

\section{RESULTS}

This section shows the results of the regressions on weight underestimation and weight overestimation. Table 4 presents the regressions of respondent weight underestimation. Respondent $\mathrm{BMI}$ correlates significantly with weight underestimation for both women and men. Men and women with long-term higher education are less likely to underestimate their weight, although the correlation is only significant at the $10 \%$ level for women. Interestingly, women in a relationship are more likely to underestimate their weight. On the basis of Model II, there appears to be no correlation between respondent weight underestimation and sibling BMI or sibling weight perceptions. However, when interaction effects between sibling gender and sibling BMI as well as sibling weight perceptions are introduced in Model III, the results change. In Table 4, it is apparent that women with a sister who underestimates her weight are more likely to also underestimate their own weight. The effect from weight underestimations of brothers is much smaller and significantly different from the effect from sisters. Female respondents with a brother who underestimates his weight are slightly less likely to underestimate their weight level compared with female respondents with a

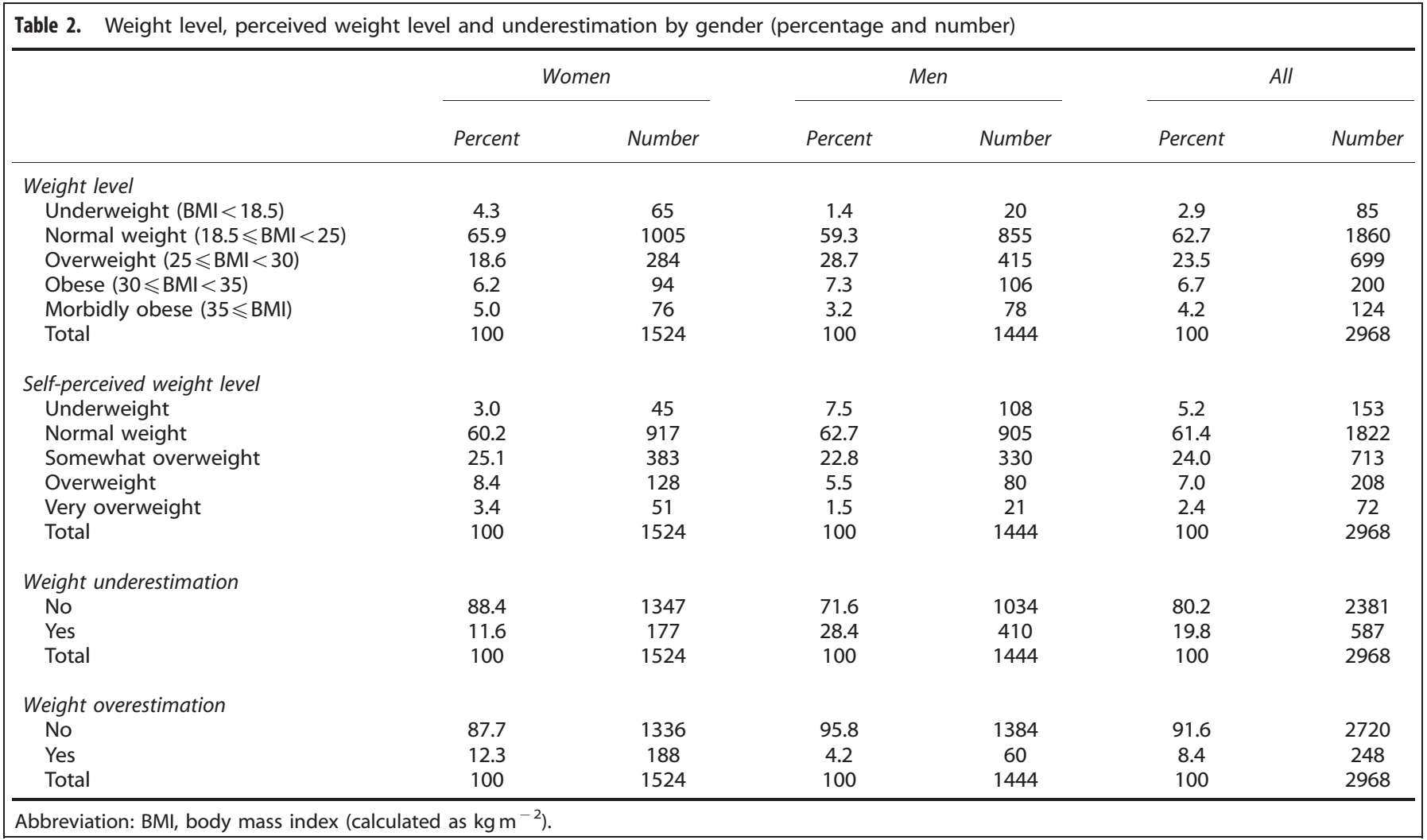


Table 3. Summary statistics (means and s.d.)

\begin{tabular}{|c|c|c|c|c|c|c|}
\hline & \multicolumn{2}{|c|}{ Women } & \multicolumn{2}{|c|}{ Men } & \multicolumn{2}{|c|}{ All } \\
\hline & Mean & s.d. & Mean & s.d. & Mean & s.d. \\
\hline Number & 1524 & & 1444 & & 2968 & \\
\hline Female & & & & & 0.51 & 0.50 \\
\hline BMI & 24.10 & 5.13 & 25.04 & 4.36 & 24.56 & 4.79 \\
\hline Age (years) & 27.36 & 4.95 & 27.16 & 4.96 & 27.26 & 4.95 \\
\hline Primary education & 0.13 & 0.34 & 0.19 & 0.39 & 0.16 & 0.37 \\
\hline Secondary education & 0.27 & 0.44 & 0.24 & 0.43 & 0.26 & 0.44 \\
\hline Vocational education & 0.11 & 0.31 & 0.25 & 0.44 & 0.18 & 0.38 \\
\hline Short-term higher education & 0.11 & 0.32 & 0.06 & 0.24 & 0.09 & 0.29 \\
\hline Middle-term higher education & 0.26 & 0.44 & 0.15 & 0.36 & 0.21 & 0.41 \\
\hline Long-term higher education & 0.12 & 0.32 & 0.10 & 0.30 & 0.11 & 0.31 \\
\hline Relationship status & 0.61 & 0.49 & 0.53 & 0.50 & 0.57 & 0.49 \\
\hline Age difference $<6$ years & 0.67 & 0.47 & 0.65 & 0.48 & 0.66 & 0.47 \\
\hline Grew up together & 0.72 & 0.45 & 0.70 & 0.46 & 0.71 & 0.45 \\
\hline Number of siblings & 1.62 & 0.82 & 1.64 & 0.81 & 1.63 & 0.81 \\
\hline Brother & 0.48 & 0.50 & 0.49 & 0.50 & 0.49 & 0.50 \\
\hline Underestimation & 0.12 & 0.32 & 0.28 & 0.45 & 0.20 & 0.40 \\
\hline Overestimation & 0.12 & 0.33 & 0.04 & 0.20 & 0.08 & 0.28 \\
\hline
\end{tabular}

brother who does not underestimate his weight level. For male respondents, there is a correlation between weight underestimation and sibling BMI. Again, the gender of the sibling has an important role in the correlation. The higher the BMI of their brother, the more likely men are to underestimate their own weight level. For men with a sister, the effect is reversed. The higher the BMI of the sister, the less likely men are to underestimate their own weight level. Furthermore, male respondents with a sibling who overestimates his or her weight are less likely to underestimate their own weight, although the correlation is only significant at the $10 \%$ level. There are no significant sibling gender differences for the correlation.

Table 5 shows results for respondent weight overestimation. Again we see gender differences. Male respondents are not influenced by their sibling, whereas female respondents are more likely to overestimate their own weight level if they have a sister who overestimates her own weight level compared with female respondents with a sister who does not overestimate her own weight level. The effect of having a brother who overestimates his weight level is reversed. Women are less likely to overestimate their own weight level if their brother overestimates his. Women who grew up with their sibling are less likely to overestimate their weight level compared with women who did not grow up with their sibling.

\section{DISCUSSION}

Previous research has shown social interactions and family context to have a significant influence on weight levels, weight behaviours and weight level perceptions. ${ }^{9}$ Gender contributes significantly to the equation. ${ }^{25}$ Within the family context, siblings especially have been shown to exert an impact on weight levels and body images. $^{20,21,22}$ However, previous research on the subject matter has concentrated on same-sex siblings and mainly women. With the analyses in the present paper, I wished to examine not only whether sibling weight level and sibling self-perceived weight level impact on own weight level perception but also how the gender of the respondent and of the sibling interacts with the correlations. I have studied whether siblings of the opposite gender exert a different influence from siblings of the same gender and what role the gender of the respondent plays.
In accordance with previous literature, the analyses show how female respondents are more likely than male respondents to overestimate their weight level, whereas male respondents are more likely than female respondents to underestimate their weight level. ${ }^{25}$ However, when looking at weight level perceptions and their interactions with gender, sibling weight and sibling weight level perceptions, the study gives new information. Not only do frequencies of weight overestimation and underestimation differ according to gender, female respondents are influenced by their siblings with regard to weight overestimation and weight underestimation, whereas male respondents are only influenced with regard to weight underestimation. Female respondents with a sister who overestimates her own weight are also more likely to overestimate their weight level compared with female respondents with a sister who does not overestimate her own weight level. On the other hand, female respondents with a brother are less likely to overestimate their own weight level if the brother overestimates his. The pattern with regard to weight underestimation of female respondents is similar. Female respondents with underestimating sisters also underestimate their own weight, whereas the opposite is true if the sibling is a brother. In line with the results of previous research and literature, ${ }^{21,22}$ the results indicate that sisters influence each other towards similar weight perceptions and body images. Sisters mimic each other's weight level perceptions. If the sister has an accurate weight level perception, the female respondent will as well, whereas female respondents with a sister who overestimates or underestimates her own weight level are more likely to have an inaccurate weight perception.

Brothers' misperceptions, on the other hand, have an opposite effect. If a woman's overweight brother does not recognise his own excess weight, it does not make her unaware of her own potential overweight, but actually even more aware. As such, her weight perception is also influenced by her brother's weight perception but apparently towards a more realistic picture of her own weight. It, therefore, appears that where sisters mimic each other's weight perceptions, an incorrect weight perception of a brother makes female respondents revise their own.

Men also take a cue from their siblings' characteristics when estimating their own weight level. However, contrary to the results for women, men appear to be more influenced by the weight of their siblings compared with their weight perceptions. When male respondents look at their brother, they are more inclined to 


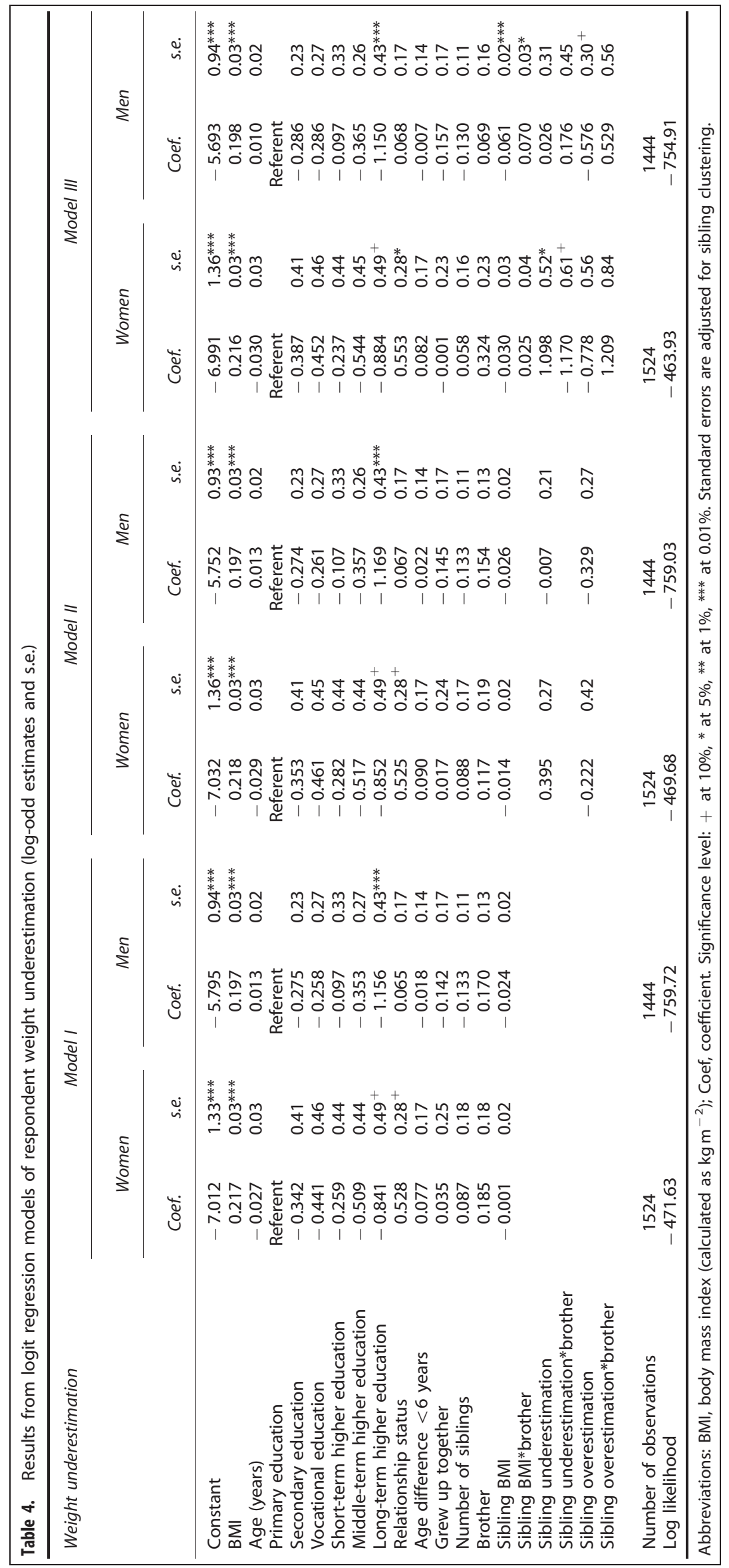




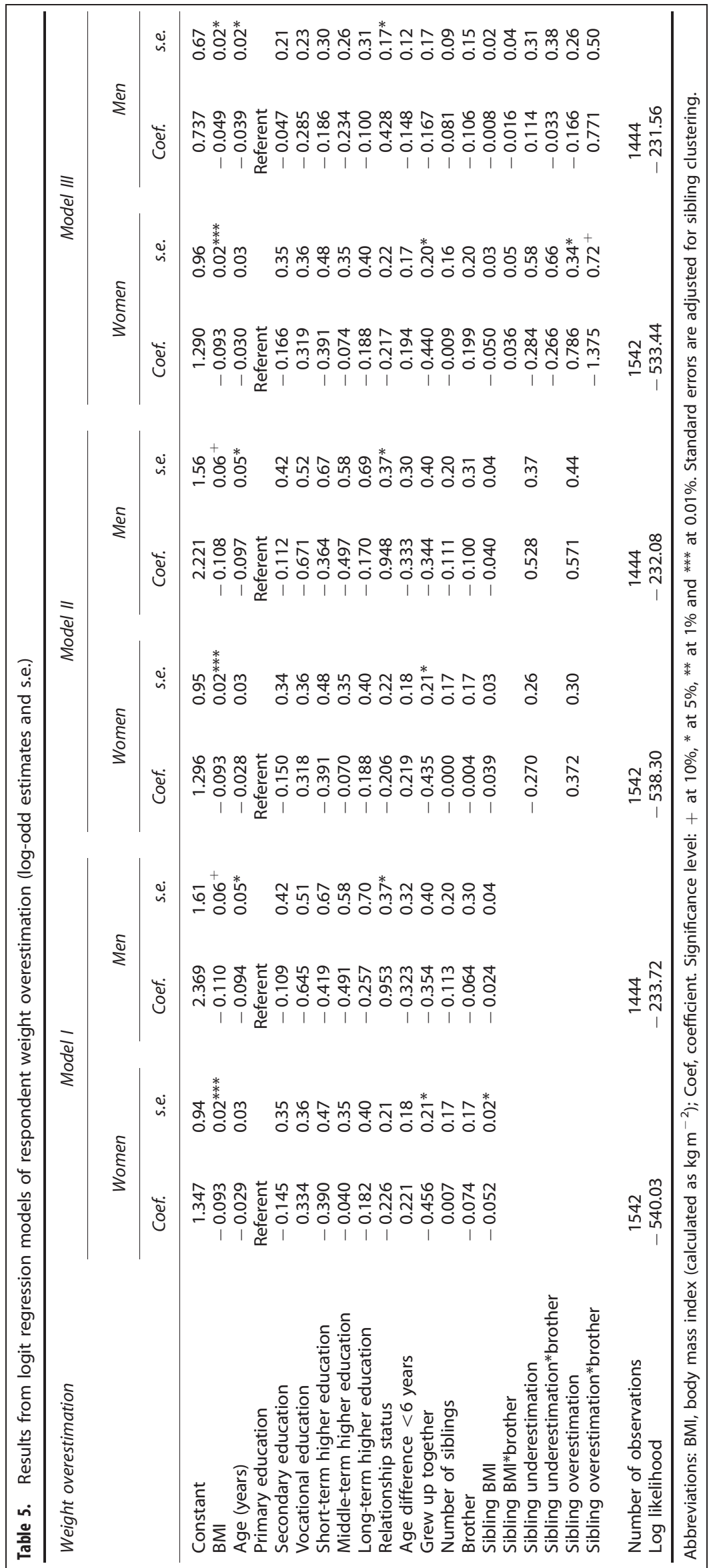


underestimate their own weight if he is overweight compared with normal weight. On the other hand, the smaller the sister he has the more likely he is to underestimate his own weight; a result that seems to duplicate the traditional ideas of the ideal genderspecific body size. ${ }^{2}$ As such, men also engage in sibling weight comparison, but the sibling's actual weight level seems to be more important than the weight level perception. And again, we see a significant difference dependent on the gender of the sibling.

All in all, the results show indications of not only sibling influences with regard to weight level perceptions but also that the effect of sibling characteristics and weight level perceptions differs dependent on own and sibling gender. Contrary to sister pairs, opposite-sex siblings do not mimic each other when it comes to weight perception. These results appear to be in accordance with previous research on sibling weight finding greater similarities between same- than opposite-sex siblings. ${ }^{26}$

Some limitations to the study should be mentioned. First and foremost, the number of respondents limits the analyses and interpretation of the results. Especially, the low number of male respondents overestimating their weight level could prove to set a limit to the analyses possible. With $4.2 \%$ of male respondents overestimating their own weight level, a larger sample population might be needed to detect significant results. Second, variables on BMI, weight underestimation and weight overestimation are based on self-reports of height and weight. Self-reports can be subject to some measurement error with people under-reporting their weight or over-reporting their height. ${ }^{28}$ However, selfreported weight and height have proven to be reliable and valid for population studies. ${ }^{34}$ Still, to correct for these possible measurement errors, I adjusted BMI measures using a correction algorithm developed by Nyholm et $a l^{32}$ on Swedish data. Third, the use of the BMI as a valid measure of weight problems has been debated. BMI does not distinguish fat from muscles, bones and other lean body mass, thereby overestimating the fat percentage among the more muscular. ${ }^{30}$ Therefore, some muscular individuals in this study might be misclassified as underestimating their own weight. Finally, I have only included a few measures of respondent characteristic besides the weightrelated variables. The inclusion of more individual and family background variables could have been informative but are unfortunately not available with the current data. However, although familial background has proven significant for child weight level, it does not necessarily influence sibling weight perception transference. Only if parents' with specific weight perceptions were more likely to have children of a specific gender compositions should parental background affect mean correlations between sibling gender, sibling weight perception and own weight perception. However, expanding on the problematic in future research by including family background variables documenting possible social class differences in the effect of sibling sex composition on weight perceptions could prove interesting.

Despite these limitations to the study, the present study offers an analysis that expands on previous research and literature on weight perception, sibling influence and gender by incorporating a cross-gender analyses looking at not only within-gender influences but also at influences coming from siblings of the opposite sex. All in all, the initial presumption that the social context and especially sibling characteristics, behaviours and perceptions influence own behaviours and perceptions seem to hold good. Furthermore, the study underlines the specific importance of gender when analysing social context and its interactions with weight and body image. Most importantly, there is not only the importance of own gender but also equally so of the gender of interaction. Hence, future empirical research on weight perceptions needs to examine the relation between the two genders and its possible effect on weight-related outcomes to better understand how individuals are influenced and influence each other with regard to weight and weight practice-not only with regard to sibling effects but also to the broader societal crossgendered influences.

\section{CONFLICT OF INTEREST}

The authors declare no conflict of interest.

\section{ACKNOWLEDGEMENTS}

This study was supported by a grant from The Danish Council for Independent Research|Social Sciences.

\section{REFERENCES}

1 WHO. Obesity: Preventing and Managing the Global Epidemic. Report of a WHO Consultation, WHO Technical Report Series. World Health Organization: Geneva, Switzerland, $\mathrm{CH}, 2004$

2 Grogan S. Body Image. Understanding Body Dissatisfaction in Men, Women, and Children. Routledge: London, UK, 2008.

3 Brug J, Wammes B, Kremers S, Giskes K, Oenema A. Underestimation and overestimation of personal weight status: associations with socio-demographic characteristics and weight maintenance intentions. J Hum Nutr Diet 2006; 19: 253-262.

4 Lemon SC, Rosal MC, Zapka J, Borg A, Andersen V. Contributions of weight perceptions to weight loss attempts: differences by body mass index and gender. Body Image 2009; 6: 90-96.

5 Chang VW, Christakis NA. Self-perception of weight appropriateness in the United States. Am J Prev Med 2003; 24: 332-339.

6 OECD. Obesity and the Economics of Prevention: Fit not Fat, OECD Publishing, 2010. 7 Cash TF. Cognitive behavioral perspectives on body image. In: Cash TF, Pruzinsky T (eds). Body Image: A Handbook of Theory, Research, and Clinical Practice. Guilford Press: New York, NY, USA, 2002, pp 38-46.

8 Tantleff-Dunn S, Gokee JL. Interpersonal influences on body image development. In: Cash TF, Pruzinsky T (eds). Body Image: A Handbook of Theory, Research, and Clinical Practice. Guilford Press: New York, NY, USA, 2002, pp 108-116.

9 Smolak L. Body image development in children. In: Cash TF, Pruzinsky T (eds). Body Image: A Handbook of Theory, Research, and Clinical Practice. Guilford Press: New York, NY, USA, 2002, pp 65-73.

10 Whitchurch G, Constantine L. Systems theory. In: Boss P, Doherty W, LaRossa R, Schumm W, Steinmetz S (eds). Sourcebook of Family Theories and Methods: A Contextual Approach. Plenum Press: New York, NY, USA, 1993, pp 325-352.

11 Katzmarzyk PT, Malina RM, Perusse L, Rice T, Province MA, Rao DC et al. Familial resemblance in fatness and fat distribution. Am J Hum Biol 2000; 12: 395-404.

12 Schousboe K, Willemsen G, Kyvik KO, Mortensen J, Boomsma DI, Cornes BK et al. Sex differences in heritability of BMI: a comparative study of results from twin studies in eight countries. Twin Res 2003; 6: 409-421.

13 Dubois L, Kyvik KO, Girard M, Tatone-Tokuda F, Pérusse D, Hjelmborg J et al. Genetic and environmental contributions to weight, height, and BMI from birth to 19 years of age: an international study of over 12,000 twin pairs. PLoS One 2012; 7: e30153.

14 Segal NL, Allison DB. Twins and virtual twins: bases of relative body weight revisited. Int J Obes 2002; 26: 437-441.

15 Segal NL, Feng R, McGuire SA, Allison DB, Miller S. Genetic and environmental contributions to body mass index: comparative analysis of monozygotic twins, dizygotic twins and same-age unrelated siblings. Int J Obes 2009; 33: 37-41.

16 Berge JM. A review of familial correlates of child and adolescent obesity: what has the 21st century taught us so far? Int J Adolesc Med Health 2009; 21: 457-483.

17 Haberstick BC, Lessem JM, McQueen MB, Boardman JD, Hopfer CJ, Smolen A et al. Stable genes and changing environments: body mass index across adolescence and young adulthood. Behav Genet 2010; 40: 495-504.

18 Price J, Swigert J. Within-family variation in obesity. Econ Hum Biol 2012; 10: 333-339.

19 Martin MA. The intergenerational correlation in weight: How genetic resemblance reveals the social role in families. Am J Sociol 2008; 114: S67-S105.

20 Christakis NA, Fowler JH. The spread of obesity in a large social network over 32 years. N Engl J Med 2007; 357: 370-379.

21 Rieves L, Cash TF. Social developmental factors and women's body image attitudes. J Soc Behav Person 1996; 1: 63-78.

22 Coomber K, King RM. The role of sisters in body image dissatisfaction and disordered eating. Sex Roles 2008; 59: 81-93.

23 Wang Y, Beydoun MA. The obesity epidemic in the United States-gender, age, socioeconomic, racial/ethnic, and geographic characteristics: a systematic review and meta-regression analysis. Epidemiol Rev 2007; 29: 6-28. 
24 Martin MA, May AL, Frisco ML. Equal weights but different weight perceptions among US adolescents. J Health Psychol 2010; 15: 493-504.

25 Wardle J, Haase AM, Steptoe A. Body image and weight control in young adults: international comparisons in university students from 22 countries. Int J Obes 2006; 30: 644-651.

26 Jacobson KC, Rowe DC. Genetic and shared environmental influences on adolescent BMI: interactions with race and sex. Behav Genet 1998; 28: 265-278.

27 Jæger MM. Danish Longitudinal Survey of Youth-Children. Technical Report The Danish National Centre for Social Research: Copenhagen, Denmark, 2011.

28 Merrill RM, Richardson JS. Validity of self-reported height, weight, and body mass index: findings from the National Health and Nutrition Examination Survey, 2001-2006. Prev Chronic Dis 2009; 6: A121.

29 Cawley J. The impact of obesity on wages. J Hum Resour 2004; 39: 451-474.

30 Burkhauser RV, Cawley J. Beyond BMI: the value of more accurate measures of fatness and obesity in social science research. J Health Econ 2008; 27: 519-529.
31 Hayes AJ, Kortt MA, Clarke PM, Brandrup JD. Estimating equations to correct self-reported height and weight: Implications for prevalence of overweight and obesity in Australia. Aust N Z J Pub Health 2008; 32: 542-545.

32 Nyholm M, Gullberg B, Merlo J, Lundqvist-Persson C, Råstam L, Lindblad U. The validity of obesity based on self-reported weight and height: implications for population studies. Obesity 2007; 15: 197-208.

33 Jürges $\mathrm{H}$. True health vs response styles: exploring cross-country differences in self-reported health. Health Econ 2006; 16: 163-178.

34 McAdams MA, Van Dam RM, Hu FB. Comparison of self-reported and measured BMI as correlates of disease markers in US adults. Obesity 2007; 15: 188-196.

c) (1) $\odot$ This work is licensed under a Creative Commons Attributioncc. NonCommercial-NoDerivs 3.0 Unported License. To view a copy of this license, visit http://creativecommons.org/licenses/by-nc-nd/3.0/ 